\title{
Development of a smart ugali cooker
}

\author{
Samwel Katwale*, Ngollo Daudi, Amrani Hassan, Neema Mduma, Musa Ally and Michael \\ Kis angiri \\ School of Computational and Communication Science and Engineering (CoCSE), Nelson Mandela African \\ Institution of Science and Technology, P. O. Box 447, Arusha, Tanzania
}

Received: 12-December-2020; Revised: 20-February-2021; Accepted: 21-February-2021

(C)2021 Samwel Katwale et al. This is an open access article distributed under the Creative Commons Attribution (CC BY) License, which permits unrestricted use, distribution, and reproduction in any medium, provided the original work is properly cited.

\begin{abstract}
Ugali is a thick porridge that is one of the popular staple foods in East Africa. Traditional methods of ugali preparation, cooking, and consumption are described. Firewood has been used as the primary energy source followed by charcoal. In East Africa, electricity grids have expanded and reached a wider network, which has opened opportunities for electric cooking to domestic consumers, especially in urban that was previously dominated by charcoal, which is in scarce supply due to government regulations on environmental conservation. In this project, the smart ugali cooker was designed and developed to automate the process of cooking ugali in households which is faster, safer, and healthier. The smart Ugali cooker is an automated kitchen appliance designed to boil the mixture of water and maize flour into a dough mixture referred to as ugali. It consists of a driving motor, stirrer, flour dispenser, heat source, a cooking pan, a temperature sensor that measures the temperature of the boiling water in the pan, and the control system (Arduino board). The device has basic units that are a dispenser, stirring unit, electronic control unit, pan, and electric heater. These units were fabricated and integrated to form the complete cooking device. Thereafter, the Arduino board was programmed to control the cooking process. Cooking experiments were conducted, on the cooking duration and the texture of ugali based on water to flour ratio. The results showed that ugali was cooked after ten minutes and the quality was good for consumption. In recommendation, the rightful flour to water ratio must be applied to obtain the desired texture of ugali.
\end{abstract}

\section{Keywords}

Arduino, Control system, Stirrer, Ugali.

\section{Introduction}

Ugali is a staple food delicacy in the East Africa region, which is made from maize flour and water with a heating source. It is cooked into a dough-like consistency then served with greens or stew [1].The desired ratio of flour and water for making ugali is approximately thirty percent $(30 \% \mathrm{w} / \mathrm{v})$ [2]. Water is boiled in a cooking pan, and then about thirty percent (30\%) of flour is added. Continuous heating is applied without any interruption, to resume the boiling. The rest of the flour is added while stirring until it becomes a thick paste. The stirring will be done for the next seven up to ten minutes [3]. There are several methods for testing the ugali texture, one of them is the wall- test, where a slice of the cooked ugali is thrown to a wall. If the ugali is well cooked, it will not stick on the wall, otherwise, it is undercooked.

\footnotetext{
*Author for correspondence
}

The texture of ugali can be determined by simply pressing a finger in the cooked ugali. The pressed finger when released should not stick or contain any ugali that is the correct texture [3]. Ugali which is not cooked well will disintegrate and sticks to the hand. As [4] stated that a good ugali should not contain any lumps. Ugali is best served while still hot, usually within an hour after cooking.

The problem that has been identified with the conventional method of cooking, is that sometimes ugali gets undercooked or overcooked, thus compromising on the consistency and nutrients. Another major concern was exposure to high temperatures which leads to health deterioration. Smoke exposure leads to health complications thus cooking devices that are efficient and can address those challenges needed to be developed [5]. Besides, the benefit of electronic cooking, household clean air, less cooking time [6], and overutilization of fuel from the wood have major effects; reduction in trees, 
biodiversity, accelerating global warming [7], and pollution emissions which increase deforestation [8]. According to [9] cooking with electricity is reducing explosions thus ranked as one of the safest sources of cooking with exposure to a heat source to below level.

The main objective of this project is to develop the smart ugali cooker which is faster, safer, and healthier. To achieve this main objective, the project included the following specific objectives:

1. To design and develop a smart ugali cooker.

2. To design the stirring unit of the ugali cooker.

3. To design the heating and control system of the ugali cooker.

\section{Literature review}

The existing solutions to some of the identified problems are the nsima (ugali) cooker in Malawi for electric cooking and the gwatamatic in Zimbabwe, which is deployed in hotels, schools for a wide use of the application due to its big size and energy utilization.

The gwatamatic was for industry large applications but not suitable for home cooking because of the size, high electricity requirement, and the cost of purchase, running expenses, and maintenance. In contrast, the nshima cooker is smaller in size, patented, prototype suitable for nshima, and it was not rolled out for consumer use. These are the main gaps that the project identified, which the smart ugali cooker has attempted to address.

Top-Lit Up-Draft (TLUD) cooking method, the 2018 study of consumption was conducted to identify how ugali was prepared and the challenges encountered by the cook in Kenya. The results revealed that seven out of fifteen observations that the ugali was cooked [10]. During the cooking process, ugali requires stirring continuously, thus it forces the cook to always stand and bend to maintain control of the pot while stirring. Another challenge on cooking that the author pointed out was the pot sometimes slipped from the heat source, which made the cock to change positions. Therefore, the TLUD gasifier stove was introduced to solve those challenges, it resulted in control and stability for the cook, especially when the ugali was getting harder and thicker during the cooking process [11]. The impact of the introduced method or solution (TLUD stove) to the user was portability and reduced firewood consumption. So, the portability of the device provided convenience to cooks in terms of where they wanted to cook, its convenience since cooks could multitask [10].

The TLUD cooking technique was able to solve the portability for choosing the location for cooking and the stability of the cooking pot on the stove, which enable the cook to be comfortable while cooking. But for the current trend of science and technology, people are busy with many tasks to attend to more chores like attending to children, going through their children's homework, while tired with the day's tasks. Therefore, they still need more improvement in cooking and more automation so that they can easily manage their time.

Even though ugali is most frequently consumed in east Africa, the challenge of preparation in the homes or hotels results in inconsistency and low quality [12]. The smart Ugali cooker is an automated kitchen appliance designed to boil the mixture of water and maize flour into a dough mixture referred to as ugali. It consists of a driving motor, stirrer, flour dispenser, heat source, a cooking pan, a temperature sensor to measure the temperature of the boiling water in the pan, and the arduino board, which is the control system. The project aims to automate the conventional way of cooking ugali, through costeffective means by developing a smart ugali electric cooker. The main target and beneficiaries of the project are the home consumers. The scope of the project was to design and develop an automated device for cooking ugali.

The project argues that the smart ugali cooker has the prospect to change the cooking methods and simplify lifestyle, especially in the urban population in the East African market just like the rice cookers transformed cooking markets. A study conducted by [13] discovered that more Tanzanians are embracing cooking with electricity by using appliances that utilize energy more efficiently. The ugali cooker was designed to be faster and convenient in some ways that were not possible before. It consumes less energy compared to charcoal or firewood while it produces more consistency and reliability. The East African market has adopted this new technology through the electrical kitchen and consumer home electronics. The smart ugali cooker combines an electric heater, a pan, motorized stirring, and a fully automated control system. As a result, it increases the consistency and speed of cooking which is convenient for modern homes [14]. 


\section{Materials and methods}

\subsection{Specification and design}

The device has basic units that are a dispenser, stirring unit, electronic control unit, pan, and electric heater. The smart ugali cooker is designed for home; the model cooks $0.5 \mathrm{~kg}$ of maize flour. It is equipped with a temperature sensor, which keeps the ugali optimal temperature for serving without over-cooking it. It uses induction heating, the heater directly warming the pan. This can improve energy efficiency. The pan is made up of stainless steel, while the flour dispenser is made of plastic that withstands the heater temperatures, with a capacity that holds $0.5 \mathrm{~kg}$ of maize flour.

3.1.1Dispenser

A container that holds and feeds maize flour into the pan after water is boiled, which is accomplished by monitoring through temperature sensor DS18B20 and releasing flour by opening using the servo motor which is triggered by the control unit.

3.1.2Dispenser features

The dispenser is equipped with a hole and lid at the bottom that will release the maize flour by opening the lid using the servo motor.

3.1.3DS18B20 sensor specifications

Programmable Digital Temperature Sensor, Communicates using the 1-Wire method, Operating voltage: $3 \mathrm{~V}$ to $5 \mathrm{~V}$, Temperature Range: $-55^{\circ} \mathrm{C}$ to $+125^{\circ} \mathrm{C}$, Accuracy: $\pm 0.5^{\circ} \mathrm{C}$.

3.1.4 Stirring unit

This is a metal blade for mixing water and maize flour to the appropriate texture, which will be triggered after water, is boiled and flour released. The stirring unit is powered by an electric DC (Direct Current) motor and stirring blades embedded on the motor. A control unit through a relay switch will turn on the motor after water is boiled and flour released. Specifications of the electric motor have been presented in Table 1.

3.1.5 Electronic control unit

The control unit (an Arduino board), uses stimulus from the temperature sensor to control the cooking cycle. The device is turned on, the control unit switches on the heating element through the relay switch, monitors the temperature of the boiling water through a temperature sensor, and when the water boils, it triggers pouring of maize flour from the dispenser into the pan and stirring by turning on the stirring system through the relay switch. Then the stirring of the mixture will continue gradually for three minutes. Finally, turn off the cooker and alert the user by a brief sound of a buzzer and displaying a message on the LCD (Liquid Crystal Display) screen. 3.1.6 The pan

This is a cooking container that holds Ugali. The pan is made from stainless steel, for durability, rust-free, and a good conductor of heat, which helps in supply the heat evenly and faster cooking cycle. The dimensions of the pan are diameter $21 \mathrm{~cm}$, depth $16 \mathrm{~cm}$, which can hold up to a maximum of 5.5litres of water.

Figure 1 shows the block diagram of smart ugali cooker. Figure 2 shows the device flow chart.

Table 1 Electric motor specifications

\begin{tabular}{llll}
\hline Weight: & $2.9 \mathrm{Kg}$ & Power: & $6 \mathrm{~N} . \mathrm{m}$ \\
\hline Brand: & Branded & DC Voltage: & $12 \mathrm{~V}$ \\
\hline Country: & China & Power Source: & DC \\
\hline Current Type: & DC & Model Type: & WM6061 \\
\hline Model: & Geria Industry & Speed: & $70 \mathrm{rpm}$ \\
\hline Torque: & 3360 oz-inch & Rotation: & 360 degrees \\
\hline
\end{tabular}


International Journal of Advanced Technology and Engineering Exploration, Vol 8(75)

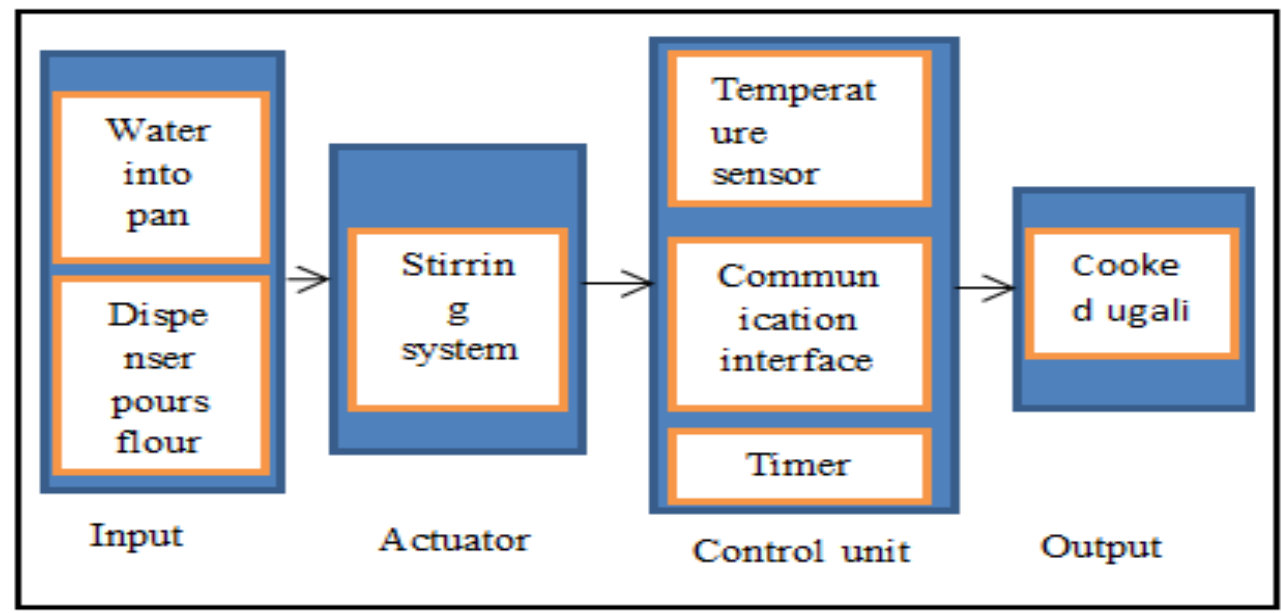

Figure 1 Block diagram of smart ugali cooker

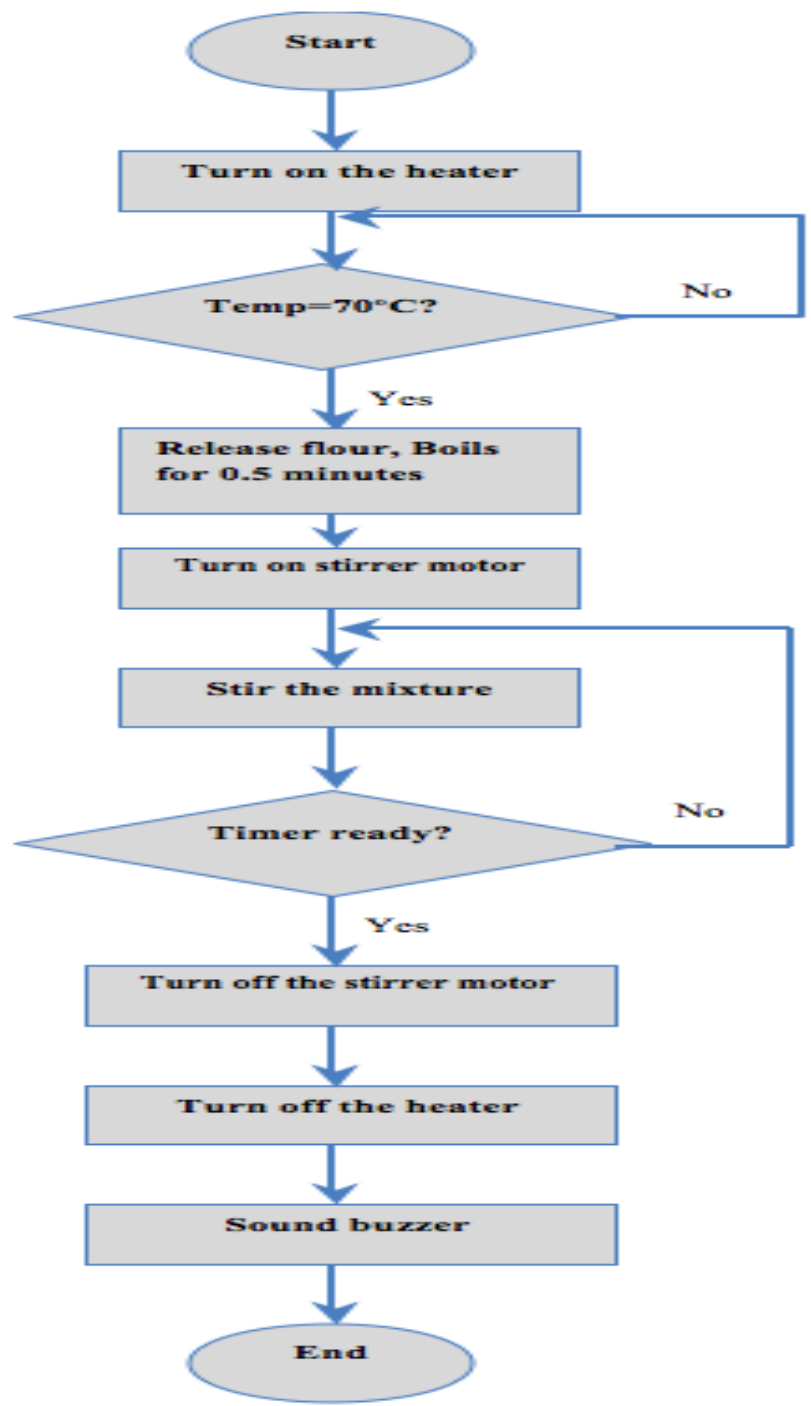

Figure 2 Device flow chart 


\subsection{Implementation}

The project was implemented through the following steps;

1. Fabrication of mechanical parts.

2. Control unit implementation.

3. Programming of the Arduino board.

4. Device Integration.

5. Testing.

\subsubsection{Fabrication of mechanical parts}

After the design process, the mechanical parts were fabricated using steel iron frame and plastic as per the specifications, the base structure holding the heater and pan, a mechanical arm holding the motor, dispenser, and control.

3.2.2Control unit

The control unit is powered by an Arduino microcontroller board, which controls the cooking cycle. Firstly, the Arduino triggers the relay to turn on the heater that boils the water to the required temperature which is measured through the temperature sensor. It then triggers the servo motor to open the dispenser lid to release the flour into the cooking pan. After, it triggers the stirring unit to stir the mixture for three minutes and finally turns off the heater, stirring unit, then triggers the buzzer as well as display a "Ready message" on the LCD screen.

3.2.3Programming of Arduino board

The Arduino IDE (Integrated Development Environment) supports languages such as $\mathrm{C}$ and $\mathrm{C}++$ using special rules of code structuring. The Arduino IDE supplies a software library that provides many common input and output procedures. The cooking process was implemented through the following methods in $\mathrm{C}$ programming language: Temperature sensor reading with library declaration, whereby signal wire was connected into pin 2 on the Arduino, then passes a one-wire reference to 'Dallas Temperature'. Relay switches for motor and heater were declared in Pin 3 and Pin 4 respectively. LCD pins (RS, E, D4, D5, D6, D7) were configured from pin 8 to 13 respectively. The buzzer pin was declared and connected to pin A0 (Digital pin 14); The arduino pin mode for the heater, motor, and buzzer was set to output; The servo was attached to Pin 6 to initiate flour release through open flour method, and closing through close flour method; The Arduino was programmed to turn off first the motor and buzzer through motor off and buzzer off methods respectively, immediately after the device is turned on and then turn on the heater through the heater on the method. After the water was boiled, flour was released from the flour dispenser through the servo motor, and the DC motor was switched on to stir the flour through the motor on the method. After the cooking process, the Arduino was programmed to turn off the heater and DC motor through the heater off and motor off methods respectively. Finally, alert the user by turning on the buzzer and display a message to the user through the LCD screen that; "Ugali is ready".

3.2.4Device configuration

The L-shaped holding frame structure, pan, heater, dispenser, DC motor, and control unit were integrated to allow them to interact and interoperate to make up the whole smart cooker.

The L-shape holding structure was manufactured to hold the other parts of the device. These parts include the heater which was mounted at the bottom base of the structure to heat the pan which was placed on top of the heater. The dispenser was mounted at the upper side of the vertical L-shaped structure, to enable flour release into the pan. The structure of the DC motor was designed in such a way that it has to be placed at the top with the stirrer facing downwards to enable the mixing of the flour in the pan. And finally, the control box was placed at the top of the DC motor structure which controls the whole cooking process.

3.2.5Testing

Different test procedures were carried out right from program code to the working/functioning of the system, to get the required standard feasible for the project. This included a temperature sensor measuring the accurate temperature as required. This was accomplished by comparing the temperature at room temperature and moderate boiling temperature with a thermometer. Dispenser releasing flour as required and the correctness of the servo motor when releasing the flour, which was accomplished by a correct rotation of the servo motor opening to 90 degrees to allow a maximum opening for the flour to be released. The timing of the stirrer at the start when the water was boiled and the flour released, and the stirrer was able to stop after the cooking time elapsed.

Figure 3 shows the finite state machine for ugali cooker. Figure 4 shows the circuit diagram for ugali cooker. 
International Journal of Advanced Technology and Engineering Exploration, Vol 8(75)

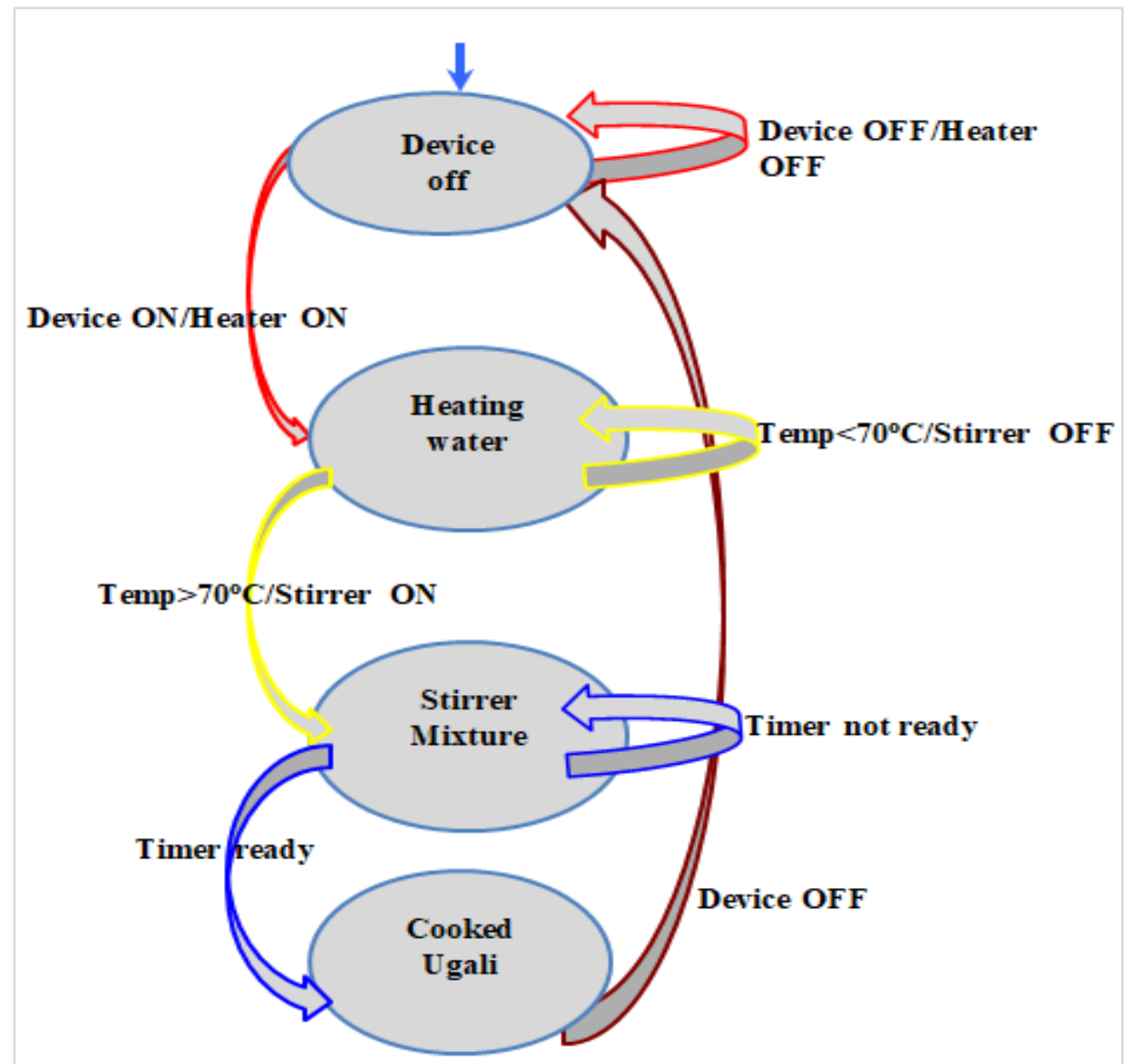

Figure 3 Finite state machine for ugali cooker

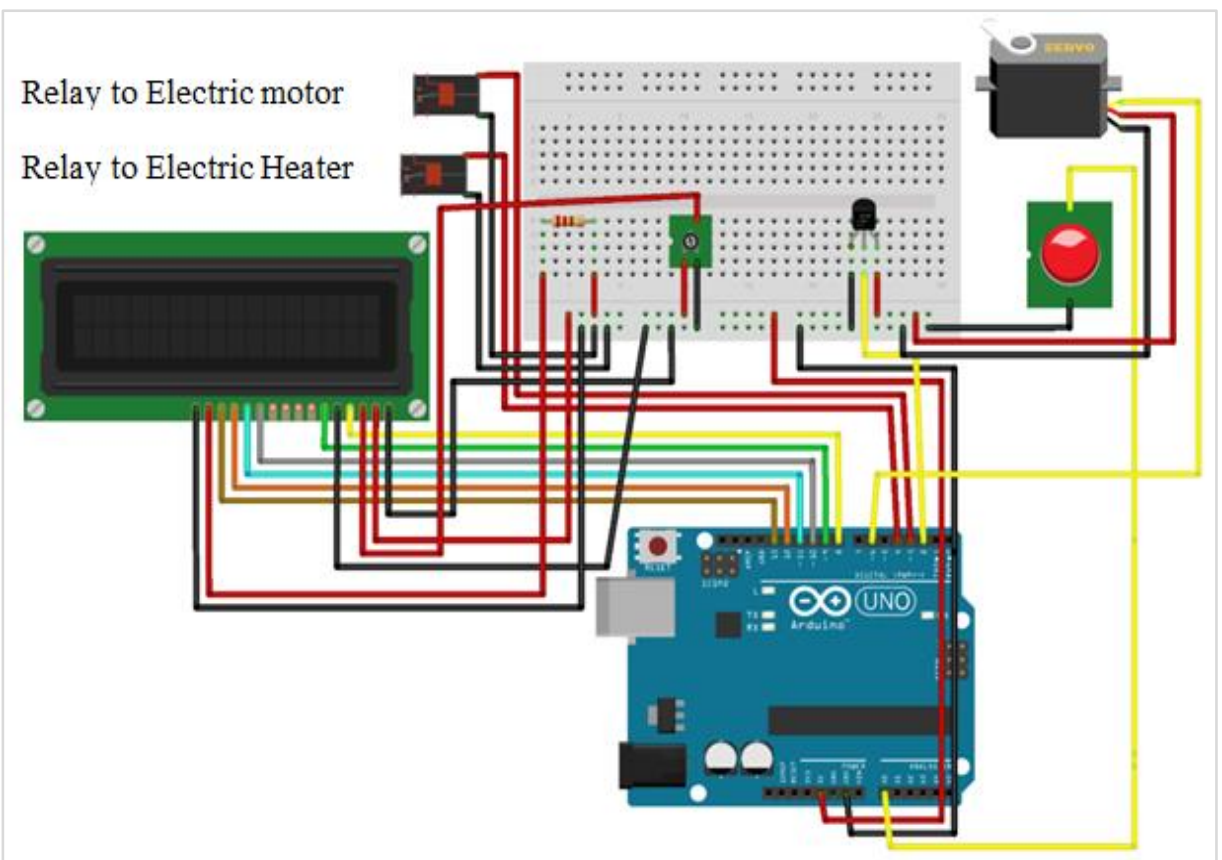

Figure 4 Circuit diagram for ugali cooker 


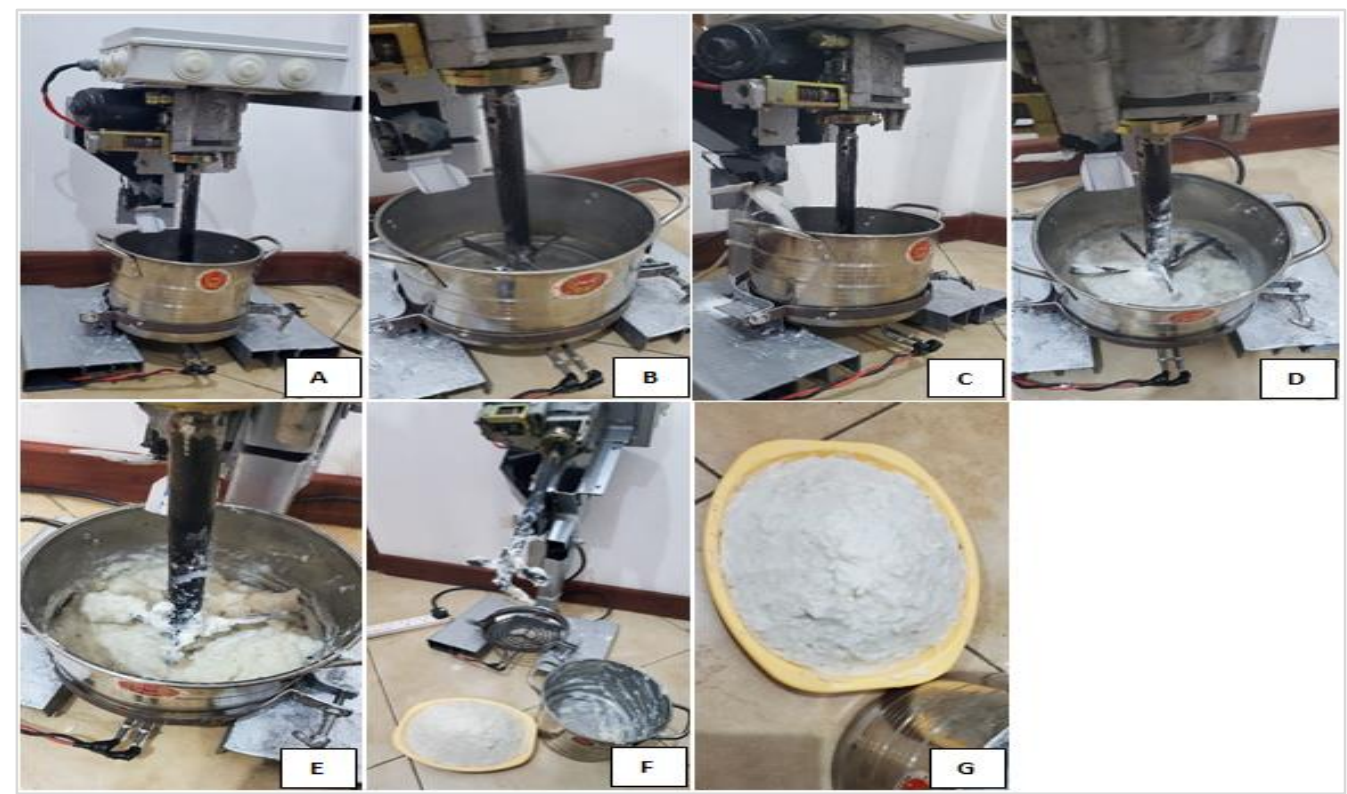

Figure 5 Pictorial representations of the cooking process

\section{Results}

Cooking experiments were conducted using the smart ugali cooker loaded with $500 \mathrm{~g}$ maize flour and $2000 \mathrm{ml}$ of water. The ugali was taken out after ten minutes and it was found to be well cooked. The overall time of cooking was maintained within a range of ten to fourteen minutes. A time of fewer than five minutes resulted in undercooking and more than fifteen minutes caused overcooking. The quality of ugali was determined by its texture, whereby several simple tests were carried out to assess the cooked ugali's texture. The 'wall-test', was used to know if the ugali was cooked properly, by throwing a slice of the ugali on the wall. Ugali which stack was considered to be not well-cooked. On the other hand, if it fell, it was considered to be well cooked [3]. The overall texture of the ugali cooked was found to be of good quality.

\section{Discussion}

Figure 5, shows a representation of a cooking process whereby, a picture of the smart ugali cooker prototype as defined in (Figure 5, A); water was poured into the pan and left to boil (Figure 5, B); After reaching the defined boiling point, flour was released into the pan in (Figure 5, C), and left to boil for 0.5 minutes (Figure 5, D); Then after 0.5 minutes, the process of flour mixing took place (Figure 5, E) and ugali was made ready and removed out of the pan (Figure 5, F), and ready to be served (Figure 5, G).
The smart ugali cooker proved to be faster and convenient with less energy consumption compared to charcoal or firewood. This improves the cooking environment of most homes. The cooker was fully automated from the boiling of water up to the time when the ugali was ready. User interaction involved loading the flour into the dispenser and water into the cooking pan as well as turning on the device. In comparison along with the results provided, the ugali cooker was able to solve the existing gap that other methods were not able to solve in the following ways;-

- In terms of size, the smart ugali cooker was relatively small and convenient as compared to automatic cooker which was designed for large scale uses.

- The cooking time was reduced to a lesser time in comparison with the Top-Lit Up-Draft (TLUD) cooking method and other local methods of cooking.

- There was no human intervention during the cooking process in the smart cooker as compared to the TLUD cooking method.

- The traditional ways of preparing ugali majorly involve direct exposure to heat since human interaction is the major activity whereas the smart ugali cooker does not expose the user to direct heat.

\subsection{Limitations}

The limitations of the study during the development of the smart ugali cooker are the following;- 
1. Fabrications of some of the mechanical parts, in terms of design, cost, and reliability.

2. Availability of the correct specification of an electric motor with the required working load.

3. The heating source dissipated more heat than initially designed.

\section{Conclusion and future work}

The design and development of a smart ugali cooker for a domestic cooking application have been presented, with the predicted and actual performance of the device. The cooking test results showed that the cooker was always capable of cooking food equivalent to $500 \mathrm{~g}$ of flour at a time, within the expected length of time. This aligns with the main focus which aimed to design and develop a cooker with consideration of labor economy, and energy cost savings. The device is simple to use and it does not require any special skills to get consistent results.

After the successful implementation of the first version of the smart ugali cooker, and through the challenges encountered, the following can be considered as future work;

- To improved design on the stirring unit

- To reduce the size of the device for portability.

- Also, the device can even be controlled remotely via a mobile phone, initiating the cooking process.

\section{Acknowledgment}

We are so grateful to thank CENIT@EA (Center of Excellence for ICT in East Africa) for the scholarship and project funding, the immediate project supervisors Dr. Mussa Ally, Dr. Michael Kisangiri, and Dr. Neema Mduma for their continued guidance and support throughout the project.

\section{Conflicts of interest}

The authors have no conflicts of interest to declare.

\section{References}

[1] Malimi KE, Ladislaus KM, Grace MN, Elifatio T, Cypriana C. Acceptability assessment of ugali made from blends of high quality cassava flour and cereal flours in the lake zone, Tanzania. Asian Food Science Journal. 2018: 2(1):1-11.

[2] Onyango AC, Walingo MK, Othuon L. Food consumption patterns, diversity of food nutrients and mean nutrient intake in relation to HIV/AIDS status in Kisumu district Kenya. African Journal of AIDS Research. 2009: 8(3):359-66.

[3] Wanjala WG, Ony ango A, Makay oto M, Ony ango C. Indigenous technical knowledge and formulations of thick (ugali) and thin (uii) porridges consumed in Kenya. African Journal of Food Science. 2016; 10(12):385-96.
[4] Mukuru SZ, Mushonga JN, Murty DS. Sorghum ugali. Proceedings of the international symposium on sorghum grain aualitv. 1981:28-30.

[5] Gitau KJ, Mutune J, Sundberg C, Mendum R, Nienga $M$. Factors influencing the adoption of biocharproducing gasifier cookstoves by households in rural Kenya. Energy for Sustainable Development. 2019; 52:63-71.

[6] Byrne R, Onsongo E, Onjala B, Chengo V, Todd JF, Ockwell D, Atela J. Electric cooking in Kenya: an actor-network map and analysis of a nascent sociotechnical innovation system.2020:1-55.

[7] Waswa F. Mcharo M. Mworia M. Declining wood fuel and implications for household cooking and diets in tigania Sub-county Kenya. Scientific African. 2020; 8:1-6.

[8] Cartagena KA, Perez JF, Chica E. Design of a top-lit up-draft micro-gasifier biomass cookstove bv thermodynamic analysis and fluent modeling. International Journal of Renewable Energy Research. 2017; 7(4):2172-87.

[9] Amesa RO. An analysis of determinants of adoption of clean energy cooking technologies and energy sources in kibera, nairobi county-kenya (Doctoral dissertation, University of Nairobi). University of Nairobi. 2019.

[10] Saraswati MS. Design improvements for top-lit UpDraft biochar-producing gasifier stove in rural Keny a from the Users' Perspective.2018.

[11] Nienga $M$, Iiyama $M$, Jamnadass $R$, Helander $H$, Larsson L, De Leeuw J, et al. Gasifier as a cleaner cooking system in rural Kenya. Journal of cleaner production. 2016: 121:208-17.

[12] Kitunda EM, Kasankala ML, Cyprian CM, Towo EE, Mushumbusi DG, Meghii PW. Sensory evaluation of ugali prepared from blends of cereal flours and high quality cassava flour in mwanza region, Tanzania. European Journal of Nutrition \& Food Safety. 2020; 12(9):52-9.

[13] Sawe E, Shuma J, Scott N. Opportunities \& Challenges for eCook Tanzania. 2019.

[14] Batchelor S, Brown E, Scott N, Sumanik-Leary J. Experiences of electric pressure cookers in East Africa. International conference on energy efficiency in domestic appliances and lighting 2019 (pp. 1-29).

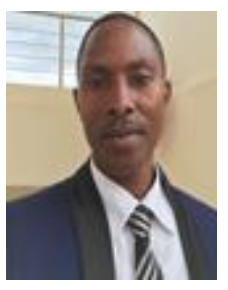

Samwel Katwale received his BSc in Computer Engineering and Information Technology from the University of Dar es Salaam, Tanzania, in 2015. Currently, he is pursuing a Master's Degree in Embedded and Mobile Systems (EMoS), at the Nelson Mandela African Institution of Science and Technology (NM-AIST). He has experience in system development and integration. His research interests include Home Automation, Health Systems, and Agriculture. Email: katwales@nm-aist.ac.tz 


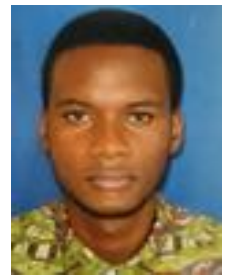

Ngollo Daudi received his BSc in Computer and Information Security from the University of Dodoma, Tanzania, in 2016. Currently, he is pursuing a Master's Degree in Embedded and Mobile Systems (EMoS) at the Nelson Mandela African Institution of Science and Technology (NM-AIST). He has experience in system development and integration. His research interests include Financial Technology, Health Systems, and Agriculture.

Email: ngollon@nm-aist.ac.tz

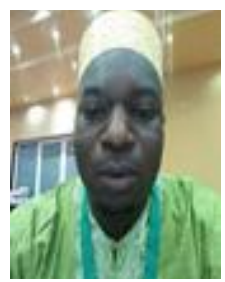

Amrani Hassan received his BTech in Information and Communication Technology from the Technical University of Mombasa, Kenya, in 2013. Currently, he is pursuing a Master's Degree in Embedded and Mobile Systems (EMoS) at the Nelson Mandela African Institution of Science and Technology (NM-AIST). He is currently working as a Senior Support Specialist at Pwani University, Kenya. He has experience in System Development, Networking, and Mobile Applications. His research interests include Big Data Analytics, Home Automation, E-Learning Systems, and E-Government.

Email: hassana@nm-aist.ac.tz

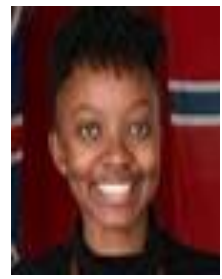

Dr. Neema Mduma is a lecturer at the Nelson Mandela African Institution of Science and Technology (NM-AIST) in Tanzania. She has $\mathrm{PhD}$ and $\mathrm{MSc}$ in Information and Communication Sciences and Engineering from NMAIST in 2020 and 2016 respectively. Neema is passionate about education particularly girls, and during her $\mathrm{PhD}$, she developed a Machine Learning model called BakiShule which aimed at preventing students from dropping out of school. Neema's efforts towards women in science have been recognized and she was given an award from the L'Oréal UNESCO as 20 young talents in Sub-Saharan Africa for the year 2020. Her research interests are Artificial Intelligence, Machine Learning, and Data Science.

Email: neema.mduma@nm-aist.ac.tz

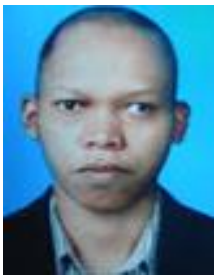

Dr. Mussa Ally Dida is a Lecturer at Nelson Mandela African Institution of Science and Technology (NM-AIST) and a Deputy Centre Leader of a Centre of Excellence for ICT in East Africa (CENIT@EA). He acquired his PhD in Information and Communication Engineering from Beijing Institute of Technology (BIT), Beijing, China in June 2017. His Masters' of Science in Telecommunication Engineering was from the University of Dodoma and his B.Sc. in Computer Engineering and Information Technology were obtained from the University of Dar es Salaam (UDSM) both obtained in 2011 and 2008 respectively. His research interests include Communication Systems Analysis, Modeling, and Development, Embedded System Development. Currently, he is working on the development of farmers' extension Support Systems and farmer's Logistic System.

Email: mussa.ally@nm-aist.ac.tz

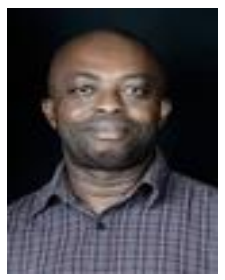

Dr. Kisangiri F. Michael has been working with NM-AIST as a lecturer then Senior lecturer since December 2011. Before joining NM-AIST, he worked with Dar-es Salaam Institute of Technology in the position of lecturer for 3 years. He is a $\mathrm{PhD}$ holder in the field of Telecommunications, with which he graduated from Wroclaw University of Technology - Poland. Currently, he is working as an academician and has supervised dozens of MSc and several $\mathrm{PhD}$ researches. He possesses good knowledge in Artificial intelligence, Antenna design, and Wireless Communication Systems. He is a fluent speaker of three languages: Swahili, English, and Polish.

Email: michael.kisangiri@nm-aist.ac.tz 